tions and/or limitations, and to encourage staff members to broaden their personal career goals.

The first group, a Budget Task Force which consisted of three junior librarians, one clerical staff member, and the associate director, worked from October 1985 to March 1986. The group was provided with confidential and sensitive information regarding all aspects of the library budget including salaries, materials budget, and general operating expenses. The main objective was to seek areas where cost savings could be made either currently or in the future. Each member was given a special assignment to gather data and present the findings to the group. The special assignments included the opportunity for savings by increasing use of work study students, centralized stack management supervision for reshelving of materials in the general collection, and reducing number of service points or desks. On several occasions, two or more of task force members collaborated on a part of the project. All ideas were considered and openly discussed within the group. The group suggested a final sixteen recommendations as being those with the most potential for acceptance due to budget and personnel restraints within the next two years.

The task force provided input into the final budget preparation, and observed the process of refinement to many of their recommendations as the recommendations were adapted to the final budget submission. This particular part of the experience brought with it some frustration when upper management made adjustments to recommendations which had been fully researched. However, the group had the opportunity to see how priorities, costs, and staffing configurations direct the underlying currents of decision-making.

The members of the task force worked diligently to provide useful and creative suggestions. Each recommendation was succinctly stated with a list of advantages, disadvantages, and suggestions for further research, where applicable. Many of the suggestions were made from personal insight and work experience with a particular area. Particular personal expertise was demonstrated in such skills as computer applications, statistical analysis, and database searching which gave the task force members new status in the eyes of their peers and notified the library administration of untapped resources.

While it is significant that ten of the sixteen recommendations were adopted in some manner in the final budget, the library gained even more from the development opportunity offered to the participating staff members. One of the librarians has since become a department head within the library system, one received a promotion to another department within the library system which was a direct result of the talents displayed during the proj ect, one has received an excellent position with a federal agency in Washington, and the clerical staff member received an excellent position in another area of the university. All of these individuals received their opportunities for advancement based upon recommendations from the associate director regarding their ability to work discreetly and competently under considerable pressure.

The next task force in this ongoing program has just been organized to review the latest goals and objectives submitted by the library's department heads and make recommendations regarding pri ority, library-wide goals, allocation of resources, compliance with the stated mission of the library, and university priority goals. This particular group is composed of four junior librarians and the associate director.

The library's Administrative Council entered into an agreement to permit this series of training task forces with some trepidation. Many members were somewhat concerned about having confidential information placed in the hands of junior librarians and clerical staff, while others felt that too much time would have to be devoted to developing a base of common knowledge upon which recommendations could be made. However, in review of the Budget Task Force's generally excellent results for both the library and the participating members, a negative situation is being addressed with a creative, effective program incorporating the tal ents of a broader range of staff.

\title{
A student assistant program for the Nineties
}

\author{
Ry F. Jay Fuller \\ Night Supervisor \\ California State University, Chico
}

Taday's academic libraries employ a great variety of people with different levels of education, expertise, and experience. Administrators, librarians, clerical, and paraprofessional staff each play a vital role in maintaining the library as the academic center for information storage and retrieval. However, some core library functions such as circulation, discharge, shelving, and even light bibli- 
ographical work are handled by individuals with little or no training in library work when they began their employment. Included in this category are student assistant employees.

One innovative student assistant program that might serve as a model for other libraries is found at the Meriam Library, California State University, Chico.

Our original student assistant program was structured so that each individual department hired and trained its own employees. When the library was relatively small and the number of student employees few, this system sufficed and ran quite well. However, we found that this compartmentalized system perpetuated significant inconsistencies in student employee training, discipline and evaluation, and developed a series of inescapable flaws as the library's collections became larger and more diversified, and the machinery to care for these collections became more complex. It also proved to be unwieldy when budget restrictions caused the number of full-time staff to decrease and the size of the student work force to increase to compensate for the loss. And there existed a distinct lack of flexibility in the movement of personnel from one department in the library to another. If a student employee wished or was needed to move to another department, that person literally had to quit, reapply to the library for a job with the other department, and be rehired.

In 1968 the library made a decision to move from this fragmented system to one that was centralized. The Department of Student Personnel was established to handle all student personnel transactions throughout the employment process. Two staff people, the manager of student personnel and the night supervisor, currently run the program, which employs 240 students. These two individuals are also in charge of the library's physical plant.

This restructuring of student employment has rectified a number of inconsistencies and solved countless problems. First, it frees the staff in technical and public service departments from the responsibility of keeping up with developments concerning the employment of student assistants. Changes in university policy, tax laws, hiring practices, wage scales and increases, etc., that involve student employees are handled by one office, and the staff in technical and public service areas can concentrate on the vital work of their units.

Second, it ensures that the hiring, training, performance expectations and evaluations of student employees are standardized and uniformly implemented. A manual was written (and is constantly updated) that outlines the basics for every student employee. All new students know what is expected of them and by what criteria they will be evaluated.

Third, it allows flexibility in using the student work force through the central referral of needs. The work force can be easily manipulated so that shortages, overloads, changes in priorities, or spe- cial projects can be dealt with efficiently by moving personnel where they are needed most, without red tape or delay.

Fourth, it guarantees that student employees are treated fairly within the employment structure. All student employees are under the authority of a central office that is directly responsible for their welfare and provides a built-in grievance system to ensure that students" complaints or problems are heard, and that any action taken by the library is consistent.

Interview and hiring procedures for potential student employees are the same, whether the individual is going to be funded by Federal Work Study or State Student Assistant monies. The manager of student personnel and the night supervisor interview and rank candidates for each type of funding, taking special note of any skills the individuals have indicated on the employment application. Those few who have word processing or typing skills are directed to further interviews with the department heads of public service units. A smaller number with other skills or expertise (carpentry, electronics, computer programming, etc.) are directed to the supervisors of any of our numerous technical service units. The majority of others who rate highly, but have limited or no specific skills, are routed to the stacking unit. Provided that interviews with unit supervisors go well, students then return to the manager of student personnel's office to fill out the necessary paperwork for university employment. Individuals who rate less highly are placed on a waiting list, forming a ready pool of students in case of student employee shortages during the academic year.

Student employees are used extensively in the public service areas. Depending on the specific needs of the department, student employees may find themselves doing jobs that, in libraries lacking effective student training programs, are often filled by full-time staff. Some copy cataloging, bibliographic verification, occasional billing, and fine collection are carried out by students. Each student, especially in circulation, must become familiar with and be able to use the library's computer system to perform a variety of tasks. They must be able to compile a new patron record, update an old record, make hold and call requests, search for title, author, call number or item requests, as well as work the desk and do routine check-outs and check-ins.

Student employees are also an important element in the technical areas of the Meriam Library's computer system operation. They are responsible for starting and shutting down the computer system, preparing the system for the next day's operation, running reports and maintenance programs, doing some onsite trouble-shooting, system upgrading, and minor terminal repair. They must also maintain, service, and trouble-shoot the library's microfiche and microform machines, as well as the videodisk-based "Infotrac" computers 


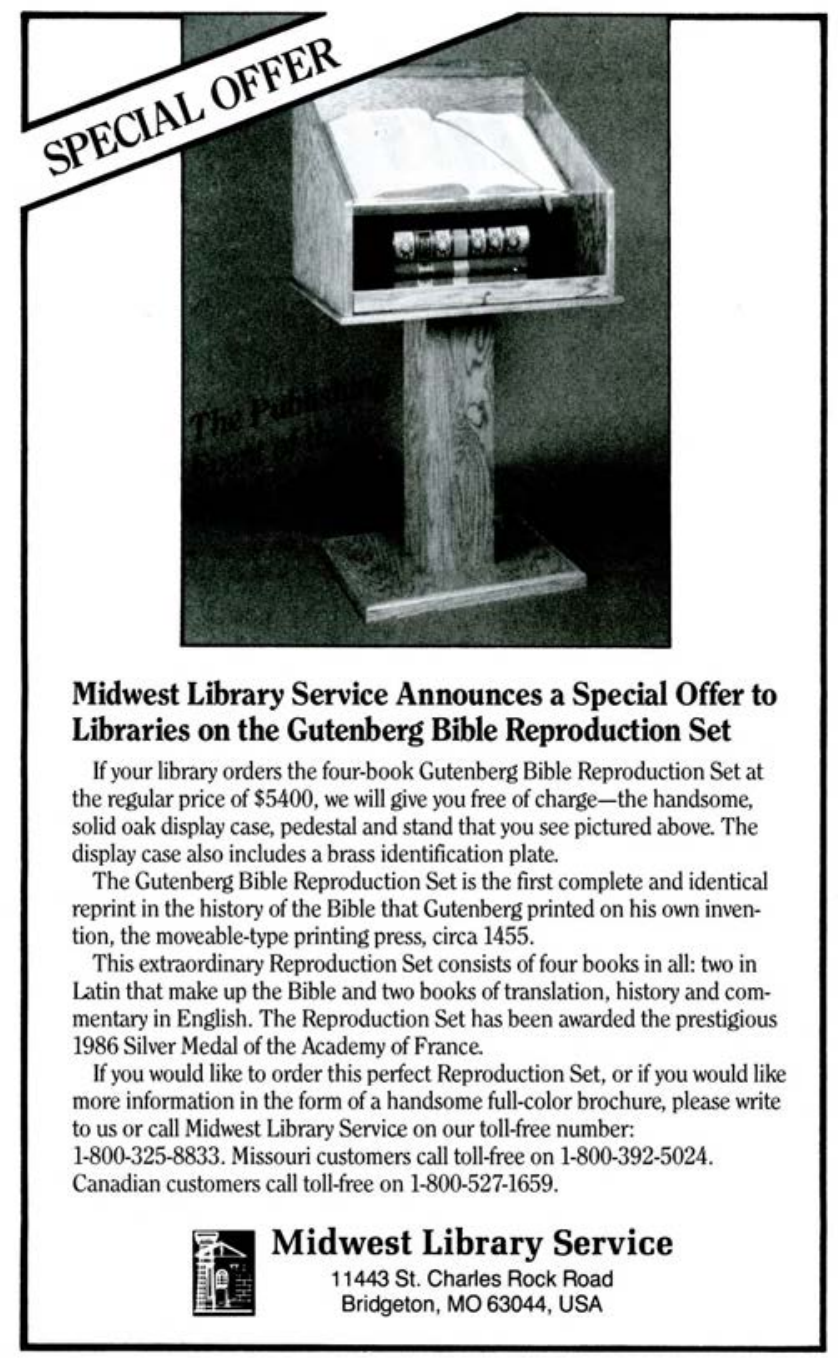


and $\mathrm{CD}$-based indexes.

As noted above, training for the majority of the student employees begins in the stacking unit where they learn the Library of Congress call num. ber system and the locations of the library's myriad collections. This familiarizes new student employees with different collections and how they relate to one another, gives them a sense of the building's physical layout, and prepares them for directing patrons in search of materials. The library considers that offering this wide range of employment is a significant contribution to the students' overall education.

As with any system, problems are sometimes encountered and our library's student assistant program is constantly being scrutinized, modified and renovated to deal with these difficulties. The number one problem is the high turnover rate of the work force. Minimum wage $(\$ 3.35)$ is the starting pay for the majority of workers. Some inevitably think this wage is inadequate compensation for their efforts and abandon their jobs. Others find the job monotonous, the hours difficult given their class loads, or have not sufficiently developed their work habits to be reliable employees. Another problem is the tendency for student employees to take vacations from work at the same time as they take vacations from their classes. This occasionally leaves the library critically short of help during the summer months and over the winter holidaystimes when the library's collections are shelf-read, shifted, and generally prepared for the next semester, and when large special projects are done, such as recarpeting, stack building and furniture rearrangement.

In order to combat these problems, we implemented a pay scale that rewards those who maintain a solid work schedule and receive a good evaluation each semester. Good work attendance, punctuality, consistent performance on the job, tact when dealing with patrons, and the ability to handle criticism and follow directions, are all rated on each evaluation. Since pay raises are not based on the duration of one's employment (there are no automatic raises), but on individual performance, most student assistants take their jobs seriously. Personnel shortages during vacation periods have been dealt with by treating semester breaks and the summer months as if those times were additional semesters. This gives student employees with poor evaluations a chance to improve them by upgrading their skills and work performance, and gives those with gond evaluations a means to move up the pay scale more quickly, provided their evaluations remain strong. Added incentive is generated by the student supervisor program, which gives a select number of outstanding student workers more responsibility, greater flexibility of action, and significantly higher pay. Starting at $\$ 4.45$ per hour, an individual in this program, with good evaluations, can quickly move up the scale and peak at $\$ 7.20$ per hour, currently the top wage permitted a student assistant employee on a California State University campus

The student supervisor is the linchpin of our student assistant program. It was developed to promote leadership and responsibility. Student assistants in this program are chiefly responsible for training new student workers, monitoring worker attendance and performance, pay voucher verification, scheduling work assignments and carrying out emergency procedures. Often these students work independently of direct staff supervision, and have the latitude to use their own initiative and resourcefulness to get the job done.

This has proven especially effective where stu dent talents and enthusiasm in relation to academic majors have been applied to library work. Engineering majors have given their coursework life by constructing machines to keep the library's shelving intact during recarpeting. In the past two years this has involved moving approximately 400,000 volumes and attendant shelving. All the work has been done by student crews, and all the collections affected have remained completely accessible during the recarpeting process. Interior design majors have renovated existing Meriam Library furniture, applying their carpentry skills to make obsolete nonprint media carrels for new equipment. Mathematics majors have had opportunities to do statistical work and to develop theoretical models for book flow and shelving distribution. Computer majors have been able to work with the library"s mini-computer and gain experience with some of the latest technology. Liberal studies majors have used their skills to write a computerized training program series that takes student trainees through the various call number systems (Library of Congress, Dewey Decimal, etc.), instructs them in the intricacies of shelving, and tests their knowledge. Many veterans of this program, including myself, have either gone on to attend library school or have been recruited to fill paraprofessional or clerical positions with the Meriam Library.

In all, our experience has shown that student employees are not only a major part of this university library's operation, but a vital-even

\section{Errata}

In the October issue "Publications" column, the title of the Society of North Carolina Archivists' directory was given incorrectly. The proper title is Archival and Manuscript Repositories in North Carolina: A Directory.

The person to contact if you wish to be considered for appointment as chair or member of a committee in the ACRL Law and Political Science Section is Carole A. Larson, Social Sciences Reference Librarian, Reference Department, University of Nebraska at Omaha Library, Omaha, NE 68182-0237. 
essential-part of the library's commitment to make information readily available to patrons. It shows that these students, like our other library employees, are capable and responsible individ- uals, willing and enthusiastic colleagues, worthy of our praise in recognition of their efforts, and one of the most effective and productive uses of our library personnel budget.

\section{Linking a high school with academic and public libraries}

\author{
By Michael W. Loder \\ Campus Librarian \\ Penn State/Schuylkill Campus
}

\author{
and James S. Fogarty \\ Curriculum/Media Specialist \\ Schuylkill Intermediate Unit
}

An electronic bulletin board, set up by the local Intermediate Unit and involving the Schuylkill Campus of Pennsylvania State University, has become a major means of communication for the librarians and libraries of the county.

In early 1984 the Intermediate Unit for Schuylkill County (I.U. 29), Pennsylvania, set up an electronic bulletin board for interlibrary cooperation. Twelve high school libraries, the Pottsville Free Public Library, and the Schuylkill Campus of Penn State agreed to share resources among themselves. An LSCA Title III grant provided a microcom puter, communications equipment, and software for each library. The I.U. sponsored training and provided a host computer in the form of a Tandy 6000 with electronic mail capability. Libraries used the system by posting ILL and other requests and checking a general notice bulletin board and their individual mailboxes each day. An existing I.U. courier system delivered materials twice a week.

For the high school librarians, many of whom had never before looked farther than their own local public libraries for outside materials, the program was a great benefit and a major learning experience. With no ideas as to what the other high school libraries had available, many early requests were subject-based fishing expeditions: "A student needs materials on Model-T cars. Anyone have anything?" Despite this loose approach the program flourished, and within its first year more than 500 print and non-print items were exchanged.

For Penn State/Schuylkill the value of this program was at first not apparent. The I.U. needed us because the Title III grant called for cooperation between different types of libraries. But did we need the network? The campus is part of Pennsylvania State Unjversity's Commonwealth Campus System, and its library had always relied primarily on Pattee Library at University Park and the other campus libraries for meeting needs for outside material. Our hands were already full with ILL requests from our own faculty and students, and we were not particularly thrilled at the prospect of sev- eral hundred high school requests piling up on our part of the bulletin board.

Another benefit for the high schools was the availability of LIAS (Library Information Access System), Penn State's own online catalog, which the high school librarians could search by dialing a local number. Would they bother with subject requests to each other when Penn State's holdings were so accessible?

Anticipating many problems, we specified some conditions for our participation in the system. First, we would only respond to requests for specific items identified by call number. Second, the high schools first must check among their own holdings and with the Pottsville Free Public Library before coming to us. Third, we insisted that requesting libraries provide us with all the information we normally put on ILL forms.

We did receive a sorely needed microcomputer, modem, and printer. But "Free" hardware could not be the only justification for participating in a consortium with other non-academic libraries. However, as Hugh Atkinson has written, "it is not necessary for outcomes, products, and uses of networks to be the results of an equal system. " We joined the group in order to get to know our previously anonymous associates in the county and to build a shared experience and working relationships.

The Schuylkill Campus of Penn State is the only academic institution in the county. The area is predominantly rural with a scattering of towns and small cities, most of which saw their fortunes disappear in the $1950 \mathrm{~s}$ with the demand for anthracite coal. The county does not have a large professional or college-educated population; yet most of our students come from this area and many are the first in their families to attend college. Our future, both as a campus and a library, is tied to this local population. We felt that getting to know the area librarians could be important for recruitment, public re-

'Hugh C. Atkinson, "Atkinson on Networks," American Libraries, June 1987, p.432. 